\title{
Effect of an angiotensin II type 1 receptor blocker on caveolin-1 expression in prostate cancer cells
}

Agnieszka Wanda Piastowska-Ciesielska ${ }^{1}$, Marcin Kozłowski², Waldemar Wagner ${ }^{3}$, Kamila Domińska ${ }^{1}$, Tomasz Ochędalski ${ }^{1}$

1Department of Comparative Endocrinology, Faculty of Biomedical Sciences and Postgraduate Training, Medical University of Lodz, Poland

2Department of Physiological Sciences, Faculty of Veterinary Medicine, Warsaw University of Life Sciences - SGGW, Poland

3Laboratory of Cellular Immunology, Institute of Medical Biology, Polish Academy of Sciences, Lodz, Poland

Submitted: 22 September 2011

Accepted: 13 February 2012

Arch Med Sci 2013; 9, 4: 739-744

DOI: 10.5114/aoms.2012.30955

Copyright $\odot 2013$ Termedia \& Banach

\section{Abstract}

Introduction: Caveolin-1, the major structural protein of caveolae, interacts directly with the AT1 receptor. The biological functions of caveolin-1 in cancer are compound, multifaceted, and depend on cell type, tumour grade and cancer stage. The AT1-R-caveolin complex in caveolae may coordinate angiotensin II (Ang II) induced signalling. The aim of this study was to determine the effect of the angiotensin II receptor type 1 blocker candesartan on caveolin expression in human metastatic prostate adenocarcinoma cells PC-3.

Material and methods: WST-1 and BrdU assays were used as indicators of cell viability and proliferation after angiotensin II and/or candesartan stimulation. Real-time RT-PCR and western blot were used to study the effect of Ang II and/or candesartan on the expression of Cav-1 and AT1-R in PC-3 cells

Results: We found that the expression of caveolin-1 mRNA in the PC-3 cells treated with CV was significantly decreased in comparison with the control $(2.9 \pm 0.17$, $4.7 \pm 0.6, p<0.05$ ), whereas a higher caveolin-1 mRNA expression was observed in those after Ang II treatment $(6.0 \pm 0.43,4.7 \pm 0.6, p<0.05)$. Protein analysis indicate that the expression of caveolin-1 protein in the PC-3 cells treated with candesartan was significantly decreased when compared with the control $(0.69 \pm 0.05$, $1.6 \pm 0.12, p<0.05)$, whereas higher caveolin-1 protein expression was observed after Ang II treatment $(2.5 \pm 0.20,1.6 \pm 0.12, p<0.05)$.

Conclusions: These results provide new information on the action of candesartan and may improve the knowledge about AT1 receptor inhibitors, which can be potentially useful in prostate cancer therapy.

Key words: caveolin-1, angiotensin II type 1 receptor, angiotensin II, candesartan, prostate cancer.

\section{Introduction}

Previous studies on caveolin-1 (Cav-1) in prostate cancer have shown that its expression and secretion are associated with the development of prostate cancer [1]. Caveolin-1 is one of the three members of the caveolin family of proteins [2]. It is an indispensable membrane protein of approximately 21-24 $\mathrm{kDa}$, found primarily in plasma membrane caveolae, the non-clathrin coated vesicles important in endocytosis and signalling. Caveolae are known to accu-

\author{
Corresponding author: \\ Dr Agnieszka W. \\ Piastowska-Ciesielska \\ Department \\ of Comparative Endocrinology \\ Faculty of Biomedical Sciences \\ and Postgraduate Training \\ Medical University of Lodz \\ 7/9 Zeligowskiego St \\ Lodz 90-752, Poland \\ Phone/fax: +48 426779318 \\ E-mail: agnieszka.piastowska@ \\ umed.lodz.pl
}


mulate cholesterol, glycosphingolipids and signalling proteins. Although under some conditions Cav-1 may suppress tumourigenesis, it is mostly associated with cancers and contributes to malignant progression through various mechanisms $[3,4]$. In addition to its role in caveolae formation, Cav-1 also functions in cellular signalling by sequestering receptors and intracellular signalling proteins within caveolae [2]. Specific proteins such as receptor tyrosine kinases, serine/ threonine kinases, phospholipases, G protein-coupled receptors, and Src family kinases are located in lipid rafts and caveolar membranes, where they interact with Cav-1 [2, 4]. The molecular mechanisms of the initiation of Cav-1 expression in prostate cancer and other malignancies are not clear [4]. The Cav-1 and Cav-2 genes are located on human chromosome 7q31.1, a highly conserved region that encompasses a known fragile site whose deletion is associated with the loss of heterozygosity, while amplification has been reported in a variety of human cancers, including prostate cancer [5]. Over-expression of Cav-1 has been reported in various cancers, including colon, kidney, bladder, lung, pancreas and ovary cancers, and in some types of breast cancer [4]. The level of Cav-1 expression may depend on the tumour type and stage; for example, high Cav-1 levels were reported in late or advanced squamous cell carcinoma and in metastatic prostate cancer [4]. The relationship between Cav-1 over-expression in prostate cancer and an aggressive, clinically significant type of the disease has been found consistently in many studies [4].

Angiotensin II (Ang II), which is a major effector peptide of the renin-angiotensin system (RAS), is well known to be an important factor in hypertension $[6,7]$. An involvement of the local RAS with autocrineparacrine roles rather than the endocrine effect has recently been documented in relation to growth and differentiation in many organs $[8,9]$. It has been reported that Ang II is involved in the development and invasion of some cancers, including breast, ovarian and pancreatic cancers [10-12]. Ang II activates the signal transduction of mitogen-activated protein kinase and signal transducers and angiogenesis in prostate cancer cells $[8,13]$. Moreover, Ang II facilitates the secretion of some growth factors and cytokines from prostate stromal cells, resulting in cell proliferation in prostate cancer $[8,14]$. Ang II exerts major regulatory actions via activation of the $\mathrm{Gq} / 11$ protein-coupled angiotensin II receptor type 1 (AT1-R) $[9,15]$. In many tissues (including the prostate), activation of the AT1 receptor leads to cell growth and differentiation responses through downstream signalling molecules that include phospholipase C, protein kinase C (PKC), the Ras-Raf-MEK-ERK signalling pathway, and signal transducers and activators of transcription (STATs) $[15,16]$.

The aim of this study was to investigate the effect of Ang II and an AT1-R blocker (candesartan) on caveolin-1 expression in metastatic PC-3 prostate cancer cells.

\section{Material and methods}

\section{Cell line and cell culture conditions}

Metastatic prostate adenocarcinoma cells (PC-3) were obtained from ATCC and maintained in RPMI1640 (Life Technologies, Corporation) with 10\% fetal bovine serum (FBS) (Life Technologies, Corporation). The cells were maintained at $37^{\circ} \mathrm{C}$ in a humidified atmosphere of $95 \%$ air and $5 \% \mathrm{CO}_{2}$. Before each experiment, the PC-3 cells were serum-deprived and cultured in a phenol red-free medium for a period of $12 \mathrm{~h}$. In all experiments the cells were exposed to angiotensin II (10 $\mu \mathrm{M})$ (Sigma-Aldrich) and candesartan $(10 \mu \mathrm{M})$ (Astra Zeneca) for $12 \mathrm{~h}$ and $24 \mathrm{~h}$, or they were pre-treated with candesartan $(10 \mu \mathrm{M})$ for $4 \mathrm{~h}$ and cultured in a medium in the presence of angiotensin $(10 \mu \mathrm{M})$ for $12 \mathrm{~h}$ or $24 \mathrm{~h}$. For WST-1 and BrdU assays the PC -3 cells were plated at a density of $4 \times 10^{3}$ cells/well in 96-well plates. For RNA or protein extraction, the cells were grown in $8 \mathrm{~cm}^{2}$ culture dishes and at $60-70 \%$ confluence they were treated with Ang II or candesartan (CV) as described previously.

\section{Cell viability assays}

Cell viability was determined by a WST-1 (4-[3(4-iodophenyl)-2-(4-nitrophenyl)-2H-5-tetrazolio]-1, 3-benzene disulfonate) reagent (Roche Applied Science, Poland) according to the manufacturer's instructions. WST-1 allows convenient assays using a tetrazolium salt which produces water-soluble formazan. To detect the effect of Ang II and candesartan on cell viability, PC-3 cells were plated in 96-well plates at a density of $4 \times 10^{3}$ cells/well and allowed to adhere overnight before the beginning of treatment.

The cells were exposed to Ang II with or without $\mathrm{CV}$ for $12 \mathrm{~h}$ to $24 \mathrm{~h}$. Simultaneously the viability of non-treated, control cells was assessed. At the end of the exposure period, the medium was replaced with $100 \mu$ l of the ( $1: 10$ dilution) WST-1 in a fresh medium in each well and incubated for $2 \mathrm{~h}$. Absorbance was measured on an ELISA plate reader (BioTeck) at $450 \mathrm{~nm}$ with reference at $655 \mathrm{~nm}$. The effect of Ang II and CV was expressed as: (OD of treated cells/OD of non-treated cells) $\times 100$. The analysis was performed in three independent experiments.

Cellular proliferation was measured using a colorimetric immunoassay based on bromodeoxyuridine (BrdU) incorporation into the cellular DNA, following the instructions recommended by the manufacturer (Roche Applied Science). The experimental design was parallel to those set for the WST-1 assay. The cells were incubated with BrdU labelling reagent for $4 \mathrm{~h}$, followed by fixation in a FixDenat solution for $30 \mathrm{~min}$ at room temperature. 
Then, they were incubated with a $1: 100$ dilution of anti-BrdU-POD for $2 \mathrm{~h}$ at room temperature. Finally, the immune reaction was detected by adding the substrate solution, and the developed colour was measured at $450 \mathrm{~nm}$ and $650 \mathrm{~nm}$ in a microplate reader (BioTeck). The effect of Ang II and CV on cell proliferation and viability was calculated as a percentage of cell proliferation measured in the non-treated cells.

\section{Real-time reverse transcription PCR}

Total RNA was obtained using the Qiagen RNeasy Minikit. Isolated RNA samples were dissolved in RNase-free water, and RNA quantity was measured using NanoDrop (Thermo Fisher Scientific). cDNA was synthesised from $10 \mu \mathrm{g}$ of total RNA at a volume of $100 \mu \mathrm{l}$ using ImProm RT-IIM (Promega) according to the manufacturer's instructions. cDNA samples were diluted with sterile deionised water to a total volume of $100 \mu \mathrm{l}$ and $2 \mu \mathrm{l}$ was added to a PCR reaction. Real-time RT-PCR was performed using a LightCycler (Roche Diagnostics). We analysed the relative expression levels of caveolin-1 (Cav-1) and AT1-R genes. The levels were normalised to GAPDH and ACTB. The primers described in Table I were designed using Primer3 software (http://frodo.wi. mit.edu/). All analyses were performed using a LightCycler FastStartDNA Master SYBR Green I kit (Roche Diagnostics) according to the procedure provided by the producer.

\section{Western blot analysis}

Total protein extracts were isolated from cells using the RIPA protein extraction buffer, supplemented with protease and phosphatase inhibitor cocktails (Sigma-Aldrich) and 1 mM PMSF (SigmaAldrich). The lysates were centrifuged at 14,000 $\times \mathrm{g}$ and $4^{\circ} \mathrm{C}$ for $20 \mathrm{~min}$, and the pellets were discarded. Protein concentration was determined by the Bradford method (Bio-Rad) according to the manufacturer's protocol, using bovine serum albumin as a reference protein for the standard curve. The protein extracts were mixed with the Laemmli buffer, heated for $1 \mathrm{~min}$ at $100^{\circ} \mathrm{C}$. Next $30 \mu \mathrm{g}$ protein per lane was resolved in $12.5 \%$ gel using SDS-PAGE (BioRad) and transferred to PVDF membranes. The membranes were then blocked in 5\% non-fat milk/
TBST or $5 \%$ BSA/TBST for $1 \mathrm{~h}$ at room temperature. After this time they were incubated overnight at $4^{\circ} \mathrm{C}$ with selected primary antibodies: anti-caveolin-1 (sc-894) and anti-AT1-R (sc-1173) (Santa Cruz Biotechnology Inc.). After the overnight incubation, the membranes were washed three times $(3 \times 15 \mathrm{~min})$ with TBST and incubated for $1 \mathrm{~h}$ in a solution of secondary antibodies conjugated with alkaline phosphatase (Sigma-Aldrich). After the second incubation they were washed three times $(3 \times 15 \mathrm{~min})$ in the TBST buffer. The colour reaction was induced using SIGMAFAST $^{\mathrm{TM}}$ BCIP $^{\oplus} / \mathrm{NBT}$ (Sigma-Aldrich). Bands were visualised on the membranes. A densitometric analysis of protein levels was performed with ImageJ $1.34 \mathrm{~s}$ software (Wayne Rasband, National Institutes of Health, USA. http://rsb.info.nih.gov/ij/) and the results were expressed as optical density (OD). The results were normalised for glyceraldehyde-3-phosphate dehydrogenase (GAPDH (sc-59540)) (Santa Cruz Biotechnology Inc.).

\section{Statistical analysis}

WST-1 and BrdU: The experimental results are shown as the mean \pm SE. Groups were compared using ANOVA followed by the Tukey post hoc test. Significance was defined as $p<0.05$ (GraphPad Prism Software). The PCR array data were analysed by the $\Delta \Delta C t$ method [17]. An average of housekeeping genes, glyceraldehyde-3-phosphate dehydrogenase $(G A P D H)$ and $\beta$-actin (ACTB) was used to obtain the $\Delta C$ t value for each gene of interest. The $\Delta \Delta$ Ct value for each gene was calculated as the difference between the $\Delta \mathrm{Ct}$ of the treated groups and that of the control. The fold-change for each gene was calculated by the $2-\Delta \Delta C T$ method.

\section{Results}

\section{Candesartan inhibits the growth of metastatic prostate adenocarcinoma cells}

To determine whether the AT1 receptor (AT1-R) is expressed in metastatic prostate adenocarcinoma cells (PC-3), we analysed the AT1-R gene expression and protein level. As shown in Figures $1 A$ and $B$, AT1-R was expressed in the PC-3 cells and its expression did not differ between the treated and

Table I. List of primer sequences used in the study

\begin{tabular}{|lccc|}
\hline Gene & Description & Primer sequences $\left(5^{\prime} \rightarrow 3^{\prime}\right)$ & Product size $[\mathrm{bp}]$ \\
\hline ATR-1 & Angiotensin II receptor, type 1 & ATTCGACCCAGGTGATCAAA & 168 \\
& CCACCAAGCTGTTCCAAAT & \\
\hline CAV-1 & Caveolin-1 & AGTGCATCAGCCGTGTCTATTCCA & 102 \\
& & TCTGCAAGTTGATGCGGACATTGC & \\
\hline GAPDH & Glyceraldehyde-3-phosphate dehydrogenase & ACAGTCAGCCGCATCTTCTT & 91 \\
& & ACCAAATCCGTTGACTCCGA & \\
\hline ACTB & $\beta$-Actin & ACCAACTGGGACGACATGGAGAAA & 192 \\
& & TAGCACAGCCTGGATAGCAACGTA & \\
\hline
\end{tabular}


untreated cells. To investigate the effect of Ang II on metastatic prostate adenocarcinoma cells, we used the angiotensin II receptor blocker candesar$\tan (\mathrm{CV})$, which is a selective blocker for AT1-R. The results of the BrdU assay revealed that Ang II treatment significantly increased the number of PC-3 cells in comparison with the control conditions (126.4 \pm 7.13 , $p<0.05)$, as shown in Figure $1 \mathrm{C}$. Moreover, CV significantly suppressed the cell growth induced by Ang II treatment $(48.34 \pm 2.83, p<0.05)$. This result was confirmed by the WST-1 assay (Figure $1 \mathrm{D}$ ), which demonstrated that the viability of Ang II treated cells significantly increased in comparison with the control $(135.1 \pm 6.60, p<0.05)$ and that CV significantly suppressed the cell growth induced by Ang II (135.1 $\pm 6.60 ; 39.60 \pm 2.30, p<0.05)$.

\section{Expression of caveolin in prostate adenocarcinoma cells}

At first, we examined whether caveolin-1 mRNA and protein were expressed in PC-3 cells. The results of real-time reverse transcription $P C R$ indicate that the expression of caveolin-1 mRNA in the PC-3 cells treated with CV was significantly decreased in comparison with the control $(2.9 \pm 0.17,4.7$

A

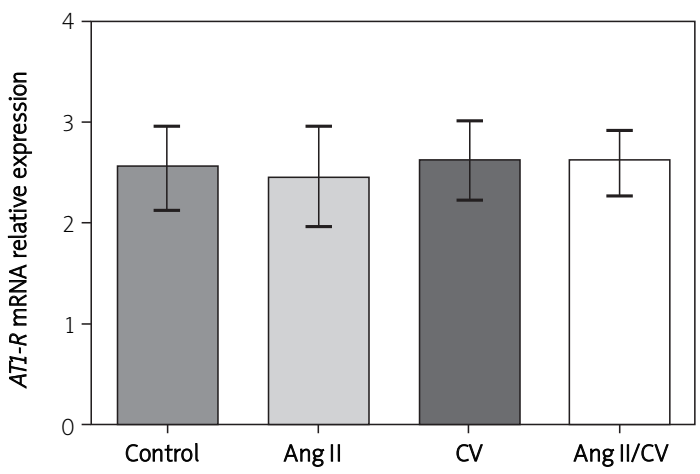

C

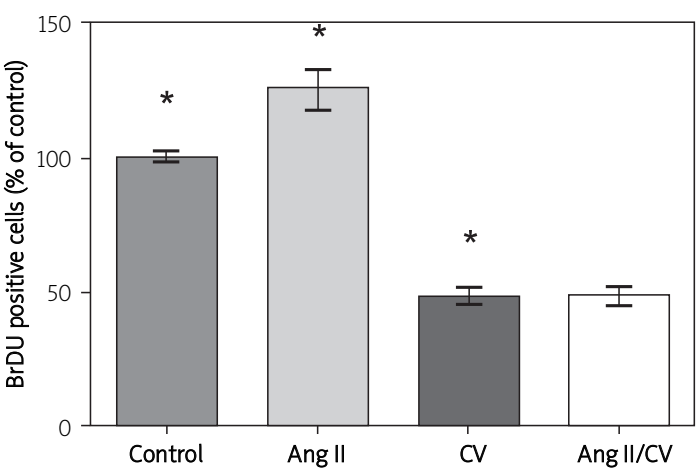

$\pm 0.6, p<0.05)$, whereas a higher caveolin-1 mRNA expression was observed in those after Ang II treatment $(6.0 \pm 0.43,4.7 \pm 0.6, p<0.05)$ (Figure $2 \mathrm{~A})$. A decreased caveolin-1 mRNA level was also shown in cells having undergone candesartan and angiotensin treatment $(2.7 \pm 0.39,4.7 \pm 0.6, p<0.05)$. Protein expression showed a similar pattern. The results shown in Figures $2 \mathrm{~B}$ and $\mathrm{C}$ indicate that the expression of caveolin-1 protein in the PC-3 cells treated with candesartan was significantly decreased when compared with the control $(0.69 \pm 0.05$, $1.6 \pm 0.12, p<0.05$ ), whereas higher caveolin-1 protein expression was observed after Ang II treatment $(2.5 \pm 0.20,1.6 \pm 0.12, p<0.05)$. A lower caveolin-1 protein level was also noted in cells treated with both candesartan and angiotensin in comparison with the control $(0.8 \pm 0.08,1.6 \pm 0.12, p<0.05)$.

\section{Discussion}

The strong evidence of the effects of Ang-II and candesartan (CV) on prostate cancer cells and tumour growth has been confirmed by many studies $[8,18-20]$. However, our results show for the first time that the angiotensin II receptor type 1 (AT1-R) is involved in caveolin-1 (Cav-1) expression.

\section{B}

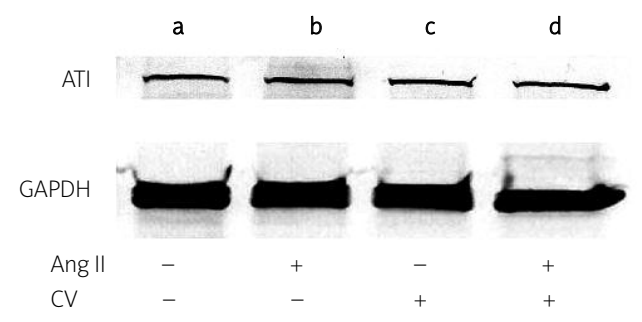

D

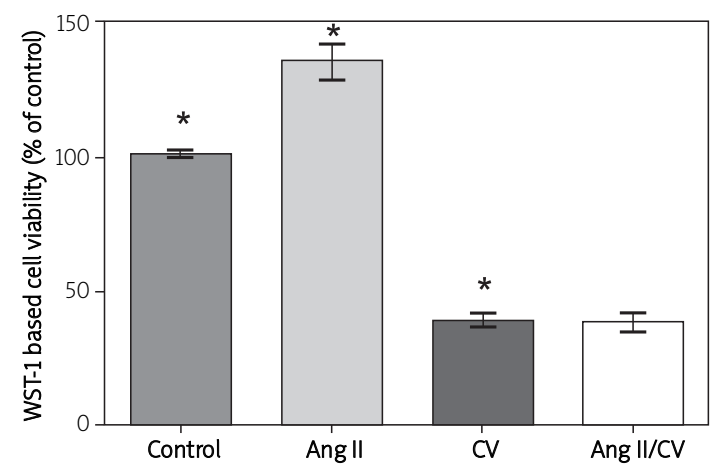

Figure 1. AT1-R expression in prostate cancer cells and inhibition of cell proliferation by candesartan in PC-3 cells. A - Total RNA from prostate adenocarcinoma cells was extracted and AT1 receptors were detected by real-time RT PCR. B - Representative Western blot with anti-AT1 receptor antibody. a - non-treated PC-3 cells, b-PC-3 cells exposed to angiotensin II $(10 \mu \mathrm{M}), \mathrm{C}-\mathrm{PC}-3$ cells exposed to candesartan $(10 \mu \mathrm{M}), \mathrm{d}-\mathrm{PC}-3$ cells pre-treated with candesartan and exposed to angiotensin II. C, D - The effect of Ang II and CV on cell proliferation and viability. Columns, mean of three different experiments; $\left.{ }^{*} p<0.05\right)$. Control - non-treated cells, Ang II - the cells exposed to angiotensin II, CV - the cells exposed to candesartan, Ang II/CV - cells pre-treated with candesartan and exposed to angiotensin II 
The AT1 receptor is a non-palmitoylated G-protein-coupled receptor expressed in many cell types, including endothelial and epithelial cells that are co-immunoprecipitates with caveolin [21]. The AT1R-caveolin complex in caveolae may coordinate Ang II induced signalling. Acting as a molecular chaperone, this protein is necessary for correct transport of AT1-R to the plasma membrane [21]. Cav-1, the major structural protein in caveolae, interacts directly with AT1-R, a subunit of Gq, Src family kinases and EGFR via a consensus motif (caveolin scaffolding domain) present in cytoplasmic domains of these signalling proteins [22]. Cav-1 has been shown to possess a double role in cancer and to act both as a tumour suppressor and a tumour promoter [1]. Evidence of a role of Cav-1 in cancer biology remains controversial even within a specific group of cancers, as Cav-1 expression varies among cancer subgroups [23]. Karam et al. have shown that Cav-1 over-expression in prostate cancer was associated with established features of aggressive tumours such as a higher Gleason grade and a pre-operative serum prostate-specific antigen (PSA) level [24]. The same group reported that Cav-1 expression was significantly associated with features of aggressive prostate cancer recurrence, such as rapid failure to respond to salvage local radiation therapy, and amplified possibility of developing early distant metastases. These results confirm a previous observation of Yang et al., who found a correlation between caveolin-1 expression and positive lymph node metastases as well as the Gleason grade of the cancer, indicating that caveolin-1 expression is associated with progression/metastasis of prostate cancer [25].

Ishizaka et al. presented an interaction between the AT1 receptor and caveolae in vascular smooth muscle cells [26]. It was the first report showing that Cav-1 expression was regulated by hormonal stimulation. Interestingly, they found that only Cav-1 mRNA, but not caveolin-2 or -3, was significantly regulated by Ang II [26]. They showed that Ang II stimulated upregulation of caveolin-1 mRNA, which confirmed our observation on metastatic prostate adenocarcinoma cells (PC-3). In contrast to our observation, they found that Ang II significantly reduced Cav-1 protein, but on the other hand $\left.{ }^{35} \mathrm{~S}\right] \mathrm{me}$ thionine labelling showed that Ang II increased caveolin biosynthesis. These results indicate the influence of Ang II on increased caveolin turnover. The data also confirm the evidence relating the AT1 receptor to the caveolae, both structurally and functionally. Aung et al. reported in their study that a decrease in PC-3 cell motility and matrix degradation capability was associated with increased Cav-1 expression [1]. These results are in opposition to the well-documented increased aggressiveness associated with Cav-1 expression in prostate cancer $[1,25,27]$. It is possible that the caveolar and noncaveolar Cav-1 may play different roles in prostate
A
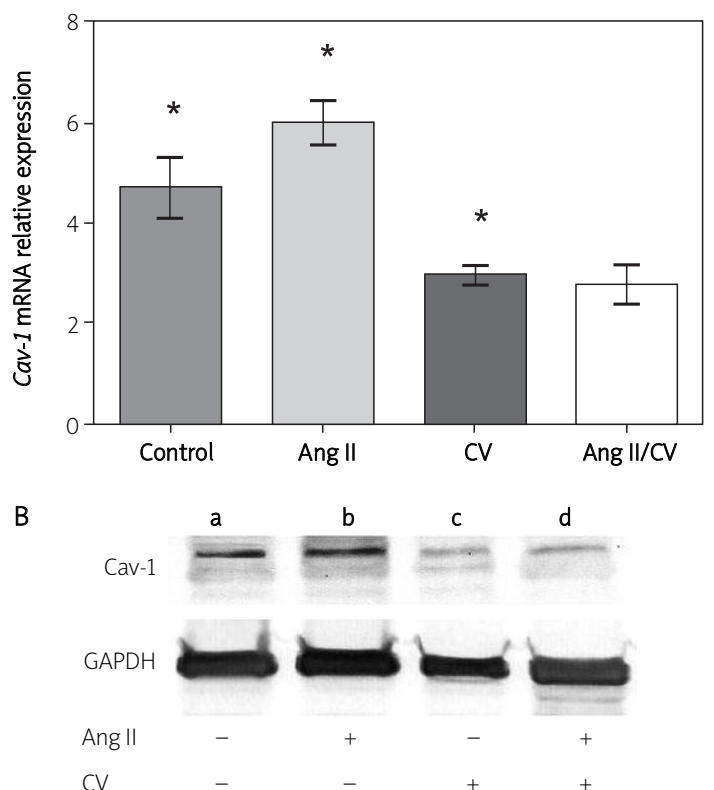

C

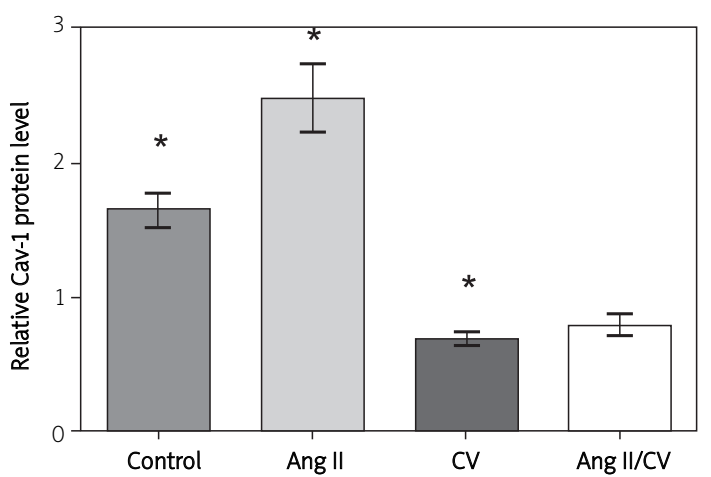

Figure 2. Effect of Ang II and CV on Cav-1 expression in prostate cancer cells. A - Total RNA from prostate adenocarcinoma cells was extracted and Cav-1 was detected by real-time RT PCR. B - Representative Western blot with anti-Cav-1 antibody. a - non-treated PC-3 cells, $b-P C-3$ cells exposed to angiotensin II $(10 \mu \mathrm{M}), \mathrm{c}-\mathrm{PC}-3$ cells exposed to candesartan $(10 \mu \mathrm{M}), \mathrm{d}-\mathrm{PC}-3$ cells pretreated with candesartan and exposed to angiotensin II. C - Relative protein levels are shown in the diagram. Columns, mean of three different experiments; $\left.{ }^{*} p<0.05\right)$. Control non-treated cells, Ang II - the cells exposed to angiotensin II, CV - the cells exposed to candesartan, Ang II/CV - cells pretreated with candesartan and exposed to angiotensin II

cancer cells, and that the elevation of non-caveolar Cav-1 increases malignant progression [1]. Targeting Cav-1 to caveolae via other molecules such as PTRF prevents migration and matrix degradation [1]. Takaguri et al. concluded that caveolin-1 was involved in the vascular remodelling induced by Ang II [22]. Cav-1 plays a critical role in the key signalling step in which angiotensin II induces the transactivation of the epidermal growth factor 
receptor (EGFR), leading to the hypertrophy and migration of vascular smooth muscle cells. Gan et al. reported that the upregulation of EGFR was involved in prostate cancer progression, but also that an impaired endocytic downregulation of EGFR contributed to oncogenic phenotypes, such as metastasis [28]. Their results additionally suggest that the therapeutic targeting of ERK signalling may have undesirable outcomes (for example, augmenting EGFR-driven motility) [28].

In conclusion, our results have demonstrated that the angiotensin II receptor type 1 blocker candesartan plays a role in the regulation of caveolin expression at the mRNA and protein levels. The present study provides new information on the action of candesartan, and may improve our knowledge about AT1 receptor inhibitors, which can be potentially useful in prostate cancer therapy.

\section{Acknowledgments}

Grant Support: this work was supported by the Grant Support: this work was supported by the and the Medical University of Lodz grant 502-03/0-07804/502-04-008 and Ministry of Science and Higher Education grant N404 107733.

\section{References}

1. Aung CS, Hill MM, Bastiani M, Parton RG, Parat MO. PTRFcavin-1 expression decreases the migration of $\mathrm{PC} 3$ prostate cancer cells: role of matrix metalloprotease 9. Eur J Cell Biol 2011; 90: 136-42.

2. Bennett N, Hooper JD, Lee CS, Gobe GC. Androgen receptor and caveolin-1 in prostate cancer. IUBMB Life 2009; 61 : 961-70.

3. Thompson TC. Metastasis-related genes in prostate cancer: the role of caveolin-1. Cancer Metastasis Rev 1998-1999; 17 439-42.

4. Thompson TC, Tahir SA, Li L, et al. The role of caveolin-1 in prostate cancer: clinical implications. Prostate Cancer Prostatic Dis 2010; 13: 6-11.

5. Timme TL, Goltsov A, Tahir S, et al. Caveolin-1 is regulated by c-myc and suppresses c-myc-induced apoptosis. Oncogene 2000; 19: 3256-65

6. Piastowska-Ciesielska AW, Drobnik J, Zarzyńska J, Domińska K, Russell JA, Ochędalski T. Influence of myocardial infarction on changes in the expression of angiotensin type 1 receptor in the rat prostate. Folia Histochem Cytobiol 2011; 49: 497-503.

7. Lubas A, Zelichowski G, Próchnicka A, Wiśniewska M, Saracyn M, Wańkowicz Z. Renal vascular response to angiotensin II inhibition in intensive antihypertensive treatment of essential hypertension. Arch Med Sci 2010; 6: 533-8.

8. Uemura H, Ishiguro H, Ishiguro Y, Hoshino K, Takahashi S, Kubota Y. Angiotensin II induces oxidative stress in prostate cancer. Mol Cancer Res 2008; 6: 250-8.

9. Sidorkiewicz M, Rebas E, Szymajda M, Ławnicka H, Pawlikowski M, Lachowicz A. Angiotensin receptors in hormoneindependent prostate cancer cell line DU145: presence of two variants of angiotensin type 1 receptor. Med Sci Monit 2009; 15: BR106-10.

10. Uemura $H$, Ishiguro $H$, Kubota Y. Pharmacology and new perspectives of angiotensin II receptor blocker in prostate cancer treatment. Int J Urol 2008; 15: 19-26.

11. Piastowska-Ciesielska AW, Płuciennik E, Wójcik-Krowiranda K, Bieńkiewicz A, Bednarek A, Ochędalski T. Analysis of the expression of angiotensin II type 1 receptor and VEGF in endometrial adenocarcinoma with different clinicopathological characteristics. Tumour Biol 2012; 33: 767-74.

12. Dominska K, Piastowska AW, Rebas E, Lachowicz-Ochedalska $A$. The influence of peptides from the angiotensin family on tyrosine kinase activity and cell viability in a human hormone-dependent prostate cancer line. Endokrynol Pol 2009; 60: 363-69.

13. Uemura $\mathrm{H}$, Ishiguro $\mathrm{H}$, Nagashima $\mathrm{Y}$, et al. Antiproliferative activity of angiotensin II receptor blocker through cross-talk between stromal and epithelial prostate cancer cells. Mol Cancer Ther 2005; 4: 1699-709.

14. Uemura $\mathrm{H}$, Nakaigawa $\mathrm{N}$, Ishiguro $\mathrm{H}$, Kubota Y. Antiproliferative efficacy of angiotensin II receptor blockers in prostate cancer. Curr Cancer Drug Targets 2005; 5: 307-23.

15. Olivares-Reyes JA, Shah BH, Hernández-Aranda J, et al. Agonist-induced interactions between angiotensin AT1 and epidermal growth factor receptors. Mol Pharmacol 2005; 68: 356-64.

16. Dominska K, Piastowska-Ciesielska AW, Lachowicz-Ochedalska A, Ochedalski T. Similarities and differences between effects of angiotensin III and angiotensin II on human prostate cancer cell migration and proliferation. Peptides 2012; 37: 200-06.

17. Livak KJ, Schmittgen TD. Analysis of relative gene expression data using real-time quantitative PCR and the 2(-Delta Delta C(T)) Method. Methods 2001; 25: 402-08.

18. Uemura H, Hasumi H, Ishiguro H, Teranishi J, Miyoshi Y, Kubota Y. Renin-angiotensin system is an important factor in hormone refractory prostate cancer. Prostate 2006; 66: 822-30.

19. Yamagishi T, Uemura H, Nakaigawa N, Noguchi K, Kubota Y. Angiotensin II blocker decreases serum prostate specific antigen in hormone refractory prostate cancer. J Urol 2005; 173: 441.

20. Bartnicki P, Majewska E, Wilk R, Baj Z, Rysz J. Captopril and losartan modify mitogen-induced proliferative response and expression of some differentiation antigents on peripheral blood mononuclear cells in chronic uraemic patients. Arch Med Sci 2009; 5: 401-07.

21. Bocanegra V, Manucha W, Pena MR, Cacciamani V, Valles PG Caveolin-1 and Hsp70 interaction in microdissected proximal tubules from spontaneously hypertensive rats as an effect of Losartan. J Hypertens 2010; 28: 143-55.

22. Takaguri A, Shirai H, Kimura K, et al. Caveolin-1 negatively regulates a metalloprotease-dependent epidermal growth factor receptor transactivation by angiotensin II. J Mol Cell Cardiol 2011; 50: 545-51.

23. Bruyere C, Abeloos L, Lamoral-Theys D, et al. Temozolomide modifies caveolin-1 expression in experimental malignant gliomas in vitro and in vivo. Transl Oncol 2011; 4: 92-100.

24. Karam JA, Lotan Y, Roehrborn CG, Ashfaq R, Karakiewicz PI, Shariat SF. Caveolin-1 overexpression is associated with aggressive prostate cancer recurrence. Prostate 2007; 67: 614-22.

25. Yang G, Truong LD, Wheeler TM, Thompson TC. Caveolin-1 expression in clinically confined human prostate cancer: a novel prognostic marker. Cancer Res 1999; 59: 5719-23.

26. Ishizaka N, Griendling KK, Lassegue B, Alexander RW. Angiotensin II type 1 receptor: relationship with caveolae and caveolin after initial agonist stimulation. Hypertension 1998; 32: 459-66

27. Mouraviev V, Li L, Tahir SA, et al. The role of caveolin-1 in androgen insensitive prostate cancer. J Urol 2002; 168: 1589-96.

28. Gan Y, Shi C, Inge L, Hibner M, Balducci J, Huang Y. Differential roles of ERK and Akt pathways in regulation of EGFR-mediated signaling and motility in prostate cancer cells. Oncogene 2010; 29: 4947-58. 